\title{
CRIAÇÃO E IMPLANTAÇÃO DO JORNAL INFORMATIVO EM SAÚDE: UM RELATO DE EXPERIÊNCIA DO PROJETO EXTENSIONISTA CIRCULAR INTERNO "FALA SÉRIO"1
}

\author{
CREATION AND IMPLEMENTATION OF THE HEALTH NEWS JOURNAL: \\ AN EXPERIENCE REPORT ON THE INTERNAL EXTENSIONIST \\ CIRCULAR PROJECT "FALA SÉRIO”
}

\section{Wellington Fernando da Silva Ferreira ${ }^{2}$, Valdoir Gonçalves Junior ${ }^{3}$ e Elia Machado de Oliveira ${ }^{4}$}

\section{RESUMO}

A inter-relação da divulgação de conhecimento científico em saúde e educação, evidenciam aspectos interdisciplinares. Para tal, através de projetos extensionistas é capaz de motivar e estabelecer estreitamento entre os universitários, bem como social e comunitário. Neste contexto objetiva-se: relatar a experiencia de implantação de um projeto extensionista de divulgação e comunicação cientifica em saúde no curso de graduação. Trata-se de um estudo em forma de relato de experiência em relação à dinâmica de ensino-aprendizagem na metodologia extensionista, de um projeto de discentes do curso de graduação em enfermagem de uma instituição de ensino superior no decorrer de 2014 e 2015. O referido relato de experiência tratou-se de um recorte, descritivo das edições publicadas da circular, das categorias temáticas estabelecidas e percepções dos participantes editores. O projeto desenvolveu treze edições em formato de jornal impresso e virtual, as quais foram publicadas mensalmente. Ao longo do projeto extensionista houve a criação de um concurso de crônicas relacionados às temáticas de saúde. As temáticas mais divulgadas foram: educação permanente; processo de formação; compreensões de aprendizagem; conhecimento da enfermagem; ensino; labor; pensamento crítico e saúde pública. Todas as edições foram anexadas em murais da instituição e enviadas por e-mails vinculados aos acadêmicos de enfermagem da instituição. Acredita-se que o projeto de divulgação em saúde atingiu aproximadamente 475 leitores mensalmente. Portanto, a trajetória dessa experiência permite vivenciar o papel extensionista. Nesse sentido, o informativo por meio de divulgação científica foi um instrumento de extensão, capaz de motivar e estabelecer estreitamento com a comunidade universitária.

Palavras-chave: Formação em saúde; Comunicação em saúde; processo ensino-aprendizagem; extensão universitária.

\section{ABSTRACT}

The interrelation of the dissemination of scientific knowledge in health and education, highlights interdisciplinary aspects. Through extension projects it is able to motivate and establish closer links between university students, as well as social and community. In this context, the aim is to report on the experience gained in implementing an extension project for the dissemination and communication of scientific knowledge ${ }^{1}$ Trabalho de extensão universitária.

${ }^{2}$ Enfermeiro, Especialista em Saúde do Idoso e Gerontologia, Mestrando do Programa de Pós-Graduação em Saúde Coletiva - Universidade Federal do Paraná - (UFPR). Curitiba - Paraná. E-mail: wellingtonferreira42@gmail.com

${ }^{3}$ Colaborador - Enfermeiro, Especialista em Metodologia do Ensino na Educação Superior, Centro Universitário Internacional - Uninter, Curitiba - Paraná. E-mail: valdoirgoncalvesjunior@gmail.com

${ }^{4}$ Orientador - Enfermeira, Especialista em Assistência de Enfermagem ao Paciente em Estado Crítico Fepar, em Comunicação Organizacional - Estácio, em Auditoria em Serviços de Saúde - Uninter, Mestre em Cirurgia - PUCPR. Diretora acadêmica Instituição INTEC - Curitiba - Paraná. E-mail: elia561@hotmail.com. 
in health in the undergraduate course. This is a study on the experience in relation to teaching and learning in the extension methodology, a project for students in the undergraduate nursing course of a higher education institution during 2014 and 2015. This experience report was a descriptive cutout, describing the published editions of the circular, the thematic categories used and perceptions of the participating editors. The project developed thirteen editions in printed and virtual newspaper format, which were monthly published. Throughout the project, there was a chronicle contest related to health themes. The most popular themes were: continuing education; training process; learning comprehensions; nursing knowledge; teaching; labor; critical thinking and public health. All editions were attached to the institution's murals and sent by e-mails linked to the institution's nursing students. It is believed that the health dissemination project reached approximately 475 readers monthly. Therefore, a trajectory of this experience allows us to experience the extension role. In this sense, the informative through scientific dissemination was an extension tool, capable of motivating and establishing closer relationship between the university community.

Keywords: Health training; Health communication; teaching and learning process; University Extension.

\section{INTRODUÇÃO}

A promoção da saúde intensifica-se através da ampliação midiática de temáticas específicas em saúde, assim como a receptividade social destas informações evidenciadas. Contudo, a compreensão da influência da comunicação humana nas assistências às populações em âmbito coletivo faz-se necessário, bem como o preparo do interlocutor e do leitor/receptor final (ZANOTTI et al., 2010; RUÃO; LOPES; MARINHO, 2012).

Deste modo, por conceitos e definições as divulgações científicas abrangem o uso de recursos técnicos, com o intuito da veiculação das informações científicas. Para as comunicações científicas, compreende-se através das transferências de conteúdos científicos especializados. Assim, as divulgações científicas prioritariamente tendem as democratizações dos acessos aos conhecimentos científicos. Portanto, os principais papéis das divulgações são os de informar; o de educar; e ao fazê-lo, promove uma visão social (BUENO, 2010; PECHULA et al., 2016).

Neste contexto, a inter-relação da área de saúde e educação tendem a ser evidenciadas em virtudes e aspectos interdisciplinares, os quais devem contribuir na vinculação do conhecimento e divulgação científica. A inter-relação, apesar de complexa, possibilita as articulações dos saberes e práticas, bem como compromissos sociais, políticos e educacionais. Para tal, a educação em saúde constitui em suma, as práticas socialmente confeccionadas em momentos e espaços históricos, acentuando as reflexões, análises, estudos e investigações pertinentes aos profissionais (SANTOS et al., 2010; GANTOS; ZAGANELL, 2013; BRÁS; FERREIRA, 2016).

Portanto, a importância de se relacionar a ideia de comunicação científica, saberes e a importância de projetos de extensão nas formações dos profissionais interdisciplinares de saúde, têm como premissa metodologias informativas tanto em níveis de graduação, especialização e pós-graduação e sua concretização faz-se necessária. Deste modo, a contemporaneidade adapta as práticas das novas 
diretrizes curriculares universitárias, quanto a investigação intencional de pensar, bem como o reordenamento das políticas públicas, que estabelecem o sistema único de saúde (SUS) (GOMES et al., 2010; HUNGER et al., 2014; VOGEL et al., 2019).

Contudo, eixos da educação permanente consolidam e ressignificam as compreensões de aprendizagem, conhecimento, ensino, labor, em espaços sociais multideterminados e socialmente construídos ao longo das décadas. Em linhas gerais, a interlocução de campos específicos, para aprimoramento de aprendizagem e pensamento crítico fomenta-se através da implementação de projetos comunicativos e de divulgação científica extensionistas, sendo esta a maneira mais real de identificação social da relação discente e comunidade (RUIZ-MORENO et al., 2005; PEREIRA; MARTINS; LANNES, 2013; FONTENELE et al., 2019).

Diante da temática supracitada, evidenciar a importância do conhecimento e da informação, utilizando atualizações e programas diversificados de extensão, na tentativa de promover cultura, entretenimento e modernidade para leitores em formação acadêmica em saúde, por meio de humor e pensamento crítico é fundamental (RUIZ-MORENO et al., 2005). O presente estudo tem como objetivo relatar a experiência de criação e implantação de um projeto extensionista de divulgação e comunicação científica em saúde no curso de graduação.

\section{METODOLOGIA}

A matriz metodológica fomenta-se, através de um estudo de relato de experiência na relação à dinâmica de ensino-aprendizagem na metodologia complexificadora, extensionista, transversalmente de projetos de discentes do curso de graduação em Enfermagem de uma instituição de ensino superior de Curitiba, Paraná, no decorrer do ano de 2014 e 2015.

Neste contexto, essa abordagem de estudo, consiste na efetivação de relato de experiência como ferramenta de pesquisa descritiva, qual apresentará uma reflexão acerca de conjuntos de ações qual aborda situações vivenciada no âmbito profissional de interesse da comunidade científica e social (GIL, 2002; GIL; YAMAUCHI, 2012).

Para tal, a integração do ensino à pesquisa e extensão objetiva-se, a concretizar processos dinâmicos de amadurecimento pessoal do acadêmico e concepções dos diferentes campos de atuação na relação da teoria e prática.

O presente artigo é parte das atividades extensionistas vivenciadas por acadêmicos, visando a divulgação e comunicação à promoção da saúde desta população universitária por meio de estratégias educativas. As ações de extensão foram desenvolvidas pelos acadêmicos integrantes do projeto de extensão "JORNAL FALA SÉRIO” (circular interno de Enfermagem). O referido relato de experiência trata-se de um recorte, descritivo das edições publicadas do circular das categorias temáticas estabelecidas e percepções dos participantes leitores e editores. 


\section{RESULTADOS E DISCUSSÕES}

\section{IDEALIZAÇÃO E IMPLANTAÇÃO DO PROJETO}

O projeto foi criado inicialmente por um acadêmico de Enfermagem eleito para substituir o representante de turma a época, e que para auxiliar semanalmente enviava para os e-mails da turma, um cronograma semanal de prováveis atividades em apoio ao cronograma das disciplinas da época. Resolvendo expandir e disseminar informações desenvolveu em parceria de outro acadêmico de Enfermagem um descritivo do projeto para o qual foi solicitado um apoio de um professional jornalista para delimitação da proposta de projeto, "Circular News", que fora apresentado posteriormente à coordenação do curso. Alguns estudos mostram que iniciativas de extensão na graduação representam ações de aprendizagem prática e teórico de experiências e imersão engajadora (BRÊTAS; PEREIRA, 2007; RUÃO; LOPES; MARINHO, 2012; SANTOS et al., 2020).

O projeto foi apresentado no dia vinte e sete do mês de março do ano de 2014. A matriz metodológica do projeto foi criada através da utilização de meios jornalísticos, com objetivo de atualização o desenvolvimento. Após ajustes realizados e apoio da coordenação, o então denominado projeto piloto extensionista "JORNAL FALA SÉRIO" circular interno fora reapresentada a direção acadêmica da época e implantado. Autores relatam a importância da estruturação adequada de projetos de extensão universitária para o bom desempenho metodológico, bem como apoio teórico (RUIZ-MORENO et al., 2005; MARANHÃO; MOURA; PINHEIRO, 2014; SOUZA; OLIVEIRA, 2015).

Figura 1 - Entrega da primeira edição noticiada no site institucional.

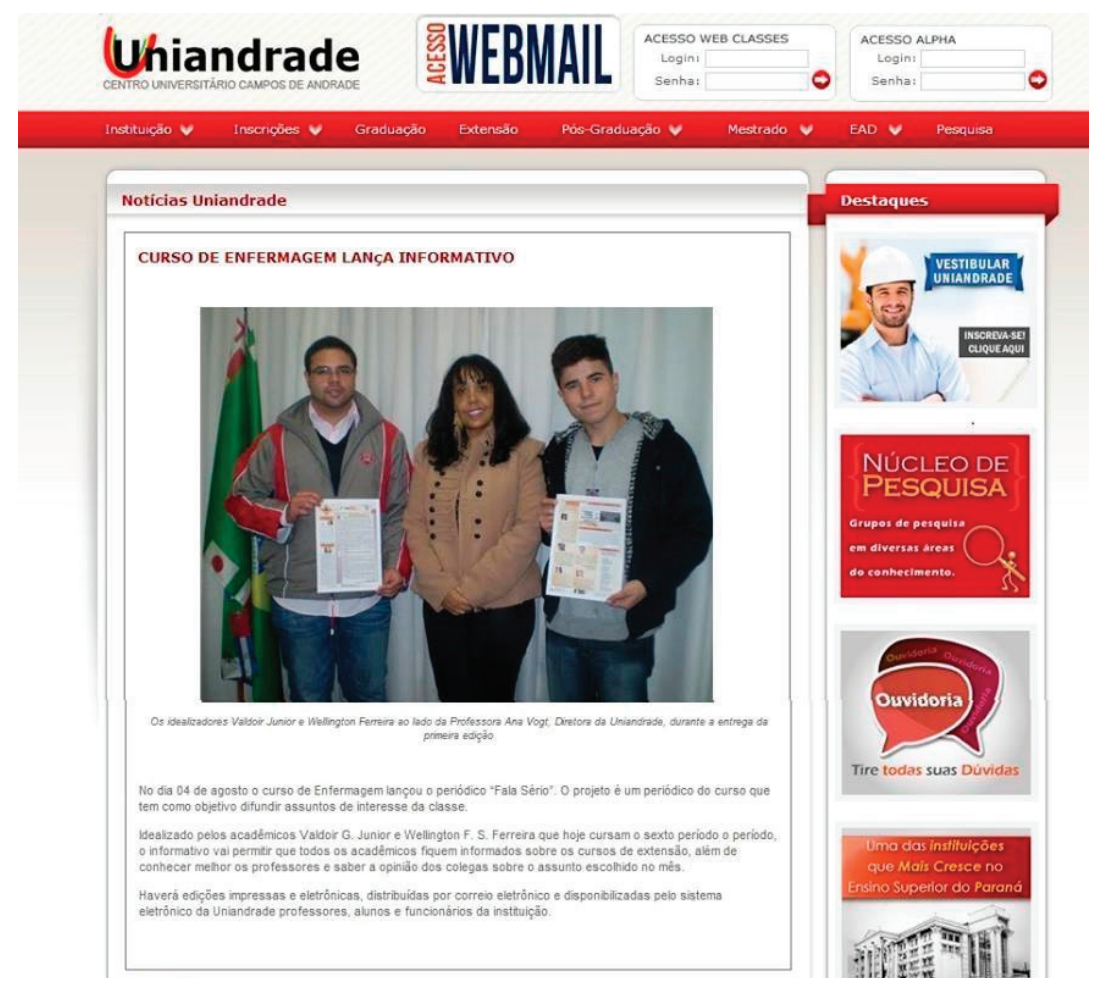

Fonte: Disponibilizado (2014) em www.uniandrade.edu.br. 
A princípio o circular interno poderia ser a voz semioficial de um grupo de acadêmicos, com apoio da instituição de ensino com suas temáticas de intermédio à saúde. Foi também um meio que facilitou a participação daqueles que desejavam colaborar com a formação profissional utilizando-se de meios jornalísticos. A elaboração do circular interno pressupôs um planejamento das tarefas, para que ao final as edições proporcionassem uma ferramenta de informação, conhecimento e entretenimento. A importância de o conhecimento ser perpassado para o público alvo é identificado em estudo de projetos universitários de extensão e com feedbacks positivos (GOMES et al., 2010; PEREIRA; MARTINS; LANNES, 2013; HUNGER et al., 2014; SOUZA; OLIVEIRA, 2015).

Deste modo, com o intuito de estabelecer e/ou repassar informação, conhecimento e diversão, foi definido onde cada seção estará situada em seu material de divulgação, e foram decididos os temas em destaque da atualidade que foram incluídos. Além disso, foi levado em consideração a importância de se ter uma linguagem ágil, criativa e com elementos que poderiam prender a atenção do leitor. Por apresentar notícias breves foi distribuído como paper via e-mail e ainda, quando autorizado, foi colocado em murais e se tornou um meio de comunicação permanente de um grupo. Para tal, a implantação da proposta na tentativa de promover cultura, entretenimento e modernidade para leitores, por meio de humor e informação, é de suma importância (RUIZ-MORENO et al., 2005; MARANHÃO; MOURA; PINHEIRO, 2014; PECHULA et al., 2016).

Decisões preliminares metodológicas pautaram-se aos responsáveis para: (características das edições, seções, matérias, repórter e elaboração de temas a tratar, editoração responsável, revisor, diagramador para a elaboração do piloto). O conteúdo da circular foi composto pelas seguintes notas: (Coluna 1: título: "palavra da coordenação"). (Coluna 2: título: "notícias em destaque”). (Coluna 3: título: “conhecendo docente biografia"). (Coluna 4: título: "anote em sua agenda"). (Coluna 5: título: “o que te espera lá fora"). (Coluna 6: título: “discussão: expressar opinião"). (Coluna 7: título: “você sabia?”). (Coluna 8: título: "papo de enfermeira"). (Coluna 9: título: "entrevistado do mês"). Para que a elaboração da entrevista fosse realizada foram feitas as seguintes perguntas: apresentação pessoal; como você se define. Porque você escolheu a enfermagem como graduação; qual seu parecer sobre o tema em destaque nesta circular; qual sua perspectiva quanto profissional. (Coluna 10: título: “campo referencial").

Todas as colunas constaram em sua diagramação fonte Arial 16; texto Calibre 10, elementos de apoio imagens ou figuras, o nome do responsável da elaboração da coluna e referência, e uma capa temática de fundo especial para cada edição. Ao decorrer das edições houve modificações estruturais de layout. A interpretação do objetivo do projeto bem como a estruturação metodológica com fins práticos faz da teoria percepções crítico-reflexivas aos estudantes (RUIZ-MORENO et al., 2005; MARANHÃO; MOURA; PINHEIRO, 2014; PECHULA et al., 2016). 


\section{RELATO DAS EDIÇÕES PUBLICADAS: TEMÁTICAS E DESAFIOS EDITORIAIS}

As edições apresentaram resultados significativos, pois foram observadas diversidades em relação ao conhecimento da informação. Instruiu a leitura, a ampliação da cultura, além de repassar atualidades informativas relacionadas, assim como demonstrou possíveis novas experiências. Despertar novas portas para o conhecimento, instituir novas diretrizes de sabedoria, colaborando com a amplitude de ideias, melhorando a categoria é imprescindível para uma formação acadêmica (BRÊTAS; PEREIRA, 2007; ZANOTTI et al., 2010; PEREIRA; MARTINS; LANNES, 2013; MOURA; PINHEIRO, 2014; PECHULA et al., 2016).

Na primeira edição, divulgada em $1^{\circ}$ de agosto de 2014, os temas abordados foram: "você conhece sua real importância enfermeiro, ampliando os conhecimentos e sua primeira especialidade!". A biografia da edição foi de uma docente especialista em gestão em saúde, saúde coletiva, urgência e emergência, preceptoria de metodologia de nível superior, mestranda em educação, a qual descreveu na coluna "papo de enfermeira" a importância da enfermagem. Na coluna "por dentro do assunto", participaram 3 (três) acadêmicos do quarto período, 1 (um) do sexto e 1 (um) do oitavo período noturno, os quais compartilharam seus pontos de vista, e assim refletiram perante o assunto principal desta circular. As temáticas corroboraram com a necessidade profissional de investigação dos saberes (PIMENTEL; MOTA; KIMURA, 2007; LEITE et al., 2009; ROSENSTOCK et al., 2011; ERDMANN; FERNANDES; TEIXEIRA, 2011).

Para a segunda edição divulgada em 02 de setembro de 2014, a temática principal foi “onde estamos, de onde viemos e para onde vamos: profissão de enfermagem", a docente biografada foi especialista em urgência e emergência e especialista em terapia intensiva, com vasta experiência na enfermagem. A coluna "papo de enfermeira" teve como tema "capacitar nossos futuros enfermeiros e atualizar seus conhecimentos específicos necessários para a prestação da assistência de enfermagem de alta complexidade ao paciente crítico". Na coluna "por dentro do assunto" participaram 1 (um) acadêmico do segundo período, 1 (um) do quinto período e 1 (um) do sexto. Estudos evidenciaram a importância da prática assistencial e humanizada, no manejo de emergência hospitalar (SANTANA, 2008; SANTANA et al., 2012; ANDRADE et al., 2016; SANCHES et al., 2016; QUEMEL et al., 2019).

Desta forma na terceira edição, publicada em 02 outubro de 2014, o tema principal foi "enfermeiros urna não é lixo (conscientizados praticamente obrigados)", a biografada da edição foi uma docente enfermeira e psicóloga, especialista em saúde mental e ciência política. Para a coluna "papo de enfermeira" o trabalho do enfermeiro na saúde mental foi temática debatida. Na coluna "por dentro do assunto", falando sobre "como um ser politicamente atuante na valorização de sua profissão" participaram 2 (dois) acadêmicos de sexto período, 1 (um) do oitavo período noturno e com a primeira participação de alunos de diurno, 1 (um) acadêmico do sétimo período (PERSEGONA et al., 2009; LESSA; ARAÚJO, 2013; SIMÕES, 2016; GARCIA et al., 2017; SILVA et al., 2017; MENDES et al., 2018). 
A quarta edição, divulgada em 02 de novembro 2014, de tema principal "enfermagem lida direta e indiretamente com a morte, acadêmico você está preparado"'. A docente biografada foi a então coordenadora de estágio, especialista em urgência e emergência. Na coluna "papo de enfermeira” tratou sobre o perfil do profissional e qualidade determinação e coragem na formação. A coluna "por dentro do assunto" falou sobre quando o profissional vai lidar direta e indiretamente com a morte, você está preparado para fazer parte destes momentos? Foram opiniões exclusivas de acadêmicos do período diurno, participaram 2 (dois) do sexto período e 1 (um) do sétimo (SANTANA, 2008; OLIVEIRA; QUINTANA; BERTOLINO, 2010; MOTA et al., 2011; SANTANA et al., 2012; SANCHES et al., 2016).

Neste contexto, a quinta edição, disseminada em 09 de fevereiro de 2015, onde o layout da circular foi modificado para melhor entreter e divulgar informações, sem perder a essência, e passou a ter um status de jornal. Os temas principais desta edição foram sobre o retorno "na sala de aula; re[pense]; a terapêutica escondida em nossas mãos; enlou-cresça; pesquisa investiga a competência moral dos enfermeiros; crônica um anjo e q+; projeto social piloto lavaedu; espaço aluno". A partir de então não houve biografia de docente na edição e sim um aumento de matérias informativas, além de charges e divulgação de eventos acadêmicos. Autores relatam que assuntos atinente ao momento acadêmico e atualidades globais podem ser complementadas, visando clarear e refletir sobre ás temáticas (ZANOTTI et al., 2010; GANTOS; ZAGANELL, 2013; TESTI et al., 2014; BRÁS; FERREIRA, 2016; PECHULA et al., 2016; ANDRADE et al., 2016).

Figura 02 - Layout das primeiras páginas da $\left(1^{\mathrm{a}}\right)$ e da última $\left(13^{\mathrm{a}}\right)$ edição publicada.
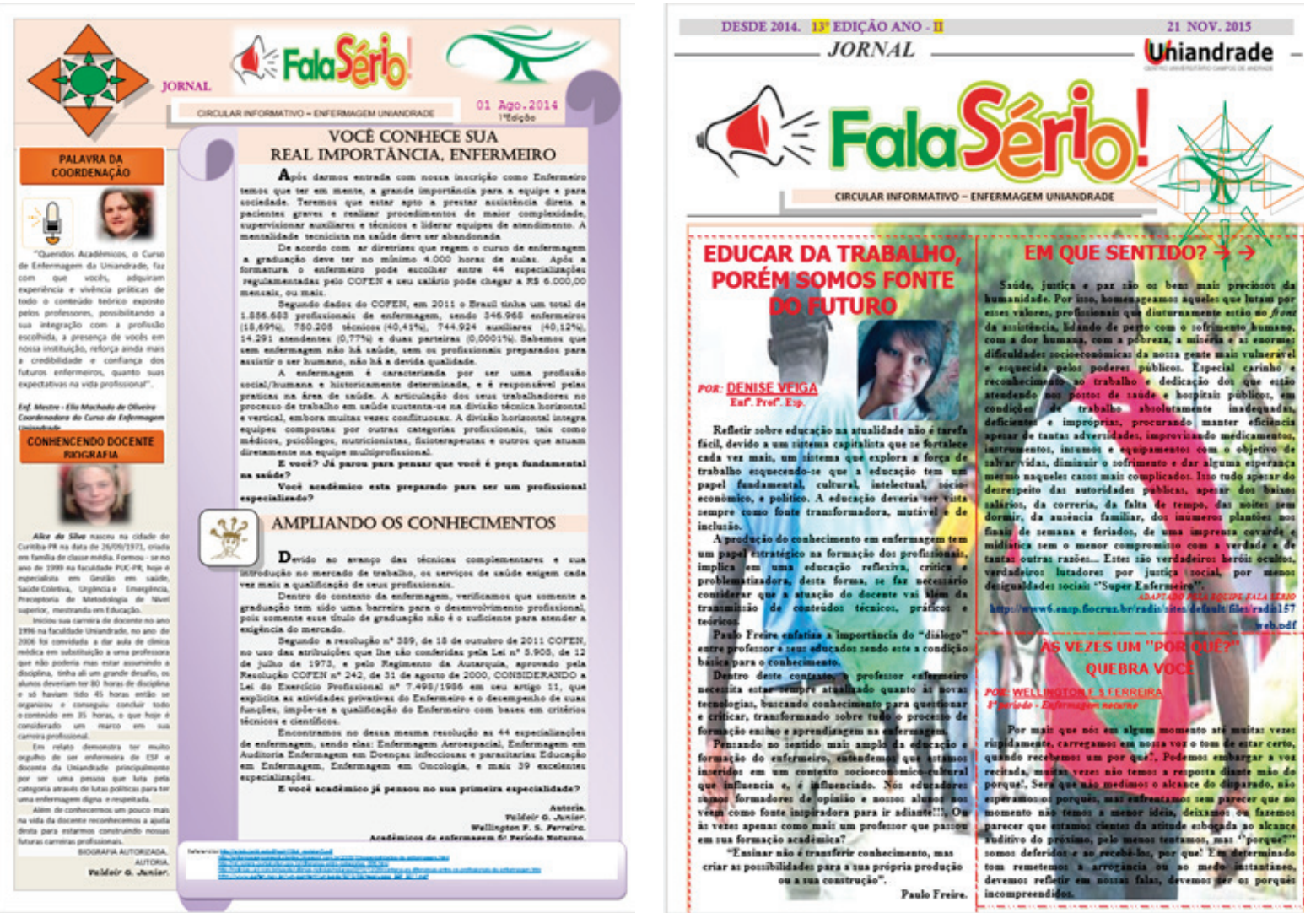

Fonte: Editores responsáveis. 
Contudo, a sexta edição, em 01 de abril de 2015, teve a temática "porque todo mundo quer ser enfermeiro; sistematização da assistência de enfermagem (SAE); cyber hipocondria e a crônica ovos de chocolate de coelho capitalista". Em suma, para a sétima edição em 10 maio de 2015 os temas foram "enfermagem a ponta do iceberg" e "aspirante a enfermeiro". Na oitava edição em 04 junho de 2015, os temas '’a enfermagem moderna", 'enfatizando saberes!!!", Sátira TCC, "pra que enfermeiro???", "Problemática de saúde pública enfermeiro", 'droga krokodilo". Nesta edição houve a participação de um acadêmico do curso de Direito do quinto período noturno, com a crônica especial sobre "a enfermagem na letra da lei na aplicação medicamentosa em pacientes" e a entrevista especial “enfim enfermeira!!!”, da acadêmica que estava findando sua trajetória e se formando em Enfermagem. E uma divulgação especial do programa anjos da enfermagem, núcleo Curitiba, da campanha de arrecadação de materiais de higiene, que foram repassados a crianças e jovens carentes em diversas instituições. Compreender as percepções do indivíduo em formação reque aprimoramento comportamental, e sabendo que poderá encontrar apoio e entretenimento em seu meio é de elevada importância (PIMENTEL; MOTA; KIMURA, 2007; PERSEGONA et al., 2009; OLIVEIRA; SILVA, 2012; TESTI et al., 2014; SIMÕES, 2016; QUEMEL et al., 2019; YUZAWA; FERREIRA; OLIVEIRA, 2019).

Na nona edição em 04 julho de 2015, teve como temáticas "quimioterapia sempre haverá mais um a ocupar a cadeira, e a sofrer, e a renovar as esperanças", "amor ao saber enfermeiro", "anamnese ganha estímulo", "santo enfermeiro; vai para o céu, ou não?", "enfermeira de plantão”. A décima edição de aniversário do projeto, divulgada em 04 agosto de 2015, os temas foram "nego sim estou respaldado", "agente da cura?", "sabe o que ela quer?", “melhoria reconhecida”, “enfermagem +humana”, "criminosos ou vítimas do crime?”, “e a saúde e sua opinião?”. Autores reforçam que articulações dos saberes e práticas, bem como compromissos sociais, políticos e educacionais fomentam a formação humanística (ANDRADE; SILVA, 2007; HONÓRIO; CAETANO, 2009; LEITE et al., 2009; ROSENSTOCK et al., 2011; ERDMANN; FERNANDES; TEIXEIRA, 2011; FERREIRA et al., 2017).

Neste período houve a criação do $1^{\circ}$ Concurso Literário de Enfermagem 'crônicas do acadêmico". Referente ao regulamento do concurso qual o circular interno "fala sério", propusera como objetivo levar entretenimento, diversão e despertar o senso crítico dos acadêmicos. Em parceria com a coordenação de Enfermagem da Uniandrade foi promovido o concurso com temática livre e sem custos. As 5 (cinco) melhores crônicas acadêmicas classificadas foram premiadas com um certificado correspondendo como atividades extracurriculares de 25 (vinte e cinco) horas, disponibilizado pela coordenação de Enfermagem da instituição e ainda foram publicadas nas edições subsequentes do circular interno as crônicas premiadas (RUIZ-MORENO et al., 2005; ZANOTTI et al., 2010; PEREIRA; RUÃO; LOPES; MARINHO, 2012; MARTINS; LANNES, 2013; PECHULA et al., 2016; FONTENELE et al., 2019).

A cônica devia ser inédita, de caráter autoral, temática livre, correlacionada aos aspectos: enfermagem e modernidade; humanização na enfermagem; cidadão/profissional cenário crítico. Quanto a classificação da crônica, os textos foram analisados pela equipe organizadora do concurso literário. 
Foram avaliados os aspectos: temática; coerência; coesão; relação com os contextos abordado (PIMENTEL; MOTA; KIMURA, 2007; PERSEGONA, et al. 2009; OLIVEIRA; QUINTANA; BERTOLINO, 2010; MOTA, et al. 2011; FERREIRA, et al. 2017).

A décima primeira edição, disponibilizada em 08 de setembro de 2015, teve o tema principal “dicotomia prazer", "meu nome é crise", "velho oeste enfermagem”, “alguém se lembrará do SUS e do enfermeiro na olimpíada de 2016?", “custos versus qualidade enfermagem”. Nesta edição foi divulgada os resultados dos ganhadores do $1^{\circ}$ Concurso Literário de Enfermagem, crônica do acadêmico. As crônicas campeãs foram: "enfermagem - uma história em cada ser"; "desigualdade social" e “Ana, Maria, Mariana ou Ana-Maria” (PERSEGONA et al., 2009; LESSA; ARAÚJO, 2013; SIMÕES, 2016; GARCIA et al., 2017; SILVA et al., 2017; MENDES et al., 2018).

A décima segunda edição, veiculada em 07 de outubro de 2015, teve como tema "a culpa é do enfermeiro", "enfermagem em prol da saúde moderna", "[re]escrevendo a história", "agravos invisíveis", "enfermagem a democracia é saúde". Na décima terceira, publicada em 21 de novembro de 2015, que seria a ultima edição do grupo e do projeto, os títulos escritos foram, “em que sentido?”, “às vezes um "por quê?, quebra você", “amigo secreto", “fala sério mesmo?”, “e por fim”, "educar da trabalho, porém somos fonte do futuro". Nessa edição a então coordenadora de estágio, especialista em urgência e emergência reflete em sua participação da última edição sobre "educação na atualidade". E o título "somos importantes sim, eu posso lhe provar" apresentou reflexões acerca da competências e habilidades exigidas pela profissão, qual contou com a participação especial da docente mestre em Bioética (PIMENTEL; MOTA; KIMURA, 2007; LEITE et al., 2009; ROSENSTOCK et al., 2011; ERDMANN; FERNANDES; TEIXEIRA, 2011).

\section{CONCLUSÃO}

O projeto jornal circular interno informativo "FALA SÉRIO" comunicação e divulgação em saúde foi confeccionado e publicado mensalmente em 13 edições em formato impresso e virtual. Ao longo do projeto extensionista houve a criação de um concurso de crônicas relacionados às temáticas da saúde.

As temáticas mais apresentadas nas edições foram: educação permanente; processo de formação; compreensões de aprendizagem; conhecimento da enfermagem; ensino; labor; pensamento crítico; saúde pública. Houve a participação de matérias redigidas e entrevistas especiais e opiniões de aproximadamente 35 acadêmicos e docentes de enfermagem. Acredita-se que o 'Projeto de Divulgação e Comunicação em Saúde" atingiu aproximadamente 475 leitores mensalmente entre acadêmicos e docentes pelos meios disponibilizados.

Em suma, com o projeto a equipe participante aprendeu a essência da escrita não como uma obrigação, mas sim como um dever no processo de formação do profissional da saúde. Percebeu que não há como ir contra o sistema, mas fazendo parte dele deve modificá-lo. 
As edições apresentaram resultados significativos, pois foram observadas diversidades em relação ao conhecimento da informação. As matérias direcionadas à saúde, à enfermagem, contemplando da diversidade de informação ao humor crítico no âmbito global, incitou os leitores a "saírem da casinha", tornando-os sujeitos críticos. A experiência relatada instruiu à leitura, à ampliação da cultura, além de repassar atualidades informativas relacionadas à saúde, assim como demonstrou possíveis novas experiências engajadoras. Despertou novas portas para o conhecimento, instituiu novas diretrizes da sabedoria, colaborando com a amplitude de ideias críticas reflexivas conforme feedback (elogios, criticas as quais foram poucas, mas construtivas, aos editores).

Ao término da última edição do jornal, houve agradecimentos a todos os colaboradores do projeto, desde escritores, participantes, produção técnica, coordenação de enfermagem e principalmente aos leitores da circular. Esperava-se que ocorresse a continuação do projeto nos anos que seguiriam. O projeto findou-se em seu segundo ano quando os editores concluíram a graduação e por não haver novos editores interessados em continuar com a confecção do jornal.

Portanto, conclui-se que a trajetória dessa experiência permite vivenciar o papel extensionista, por meio da parceria entre as ações educacionais e comunicativas. Nesse sentido, o informativo por meio de divulgação científica foi um instrumento de extensão, capaz de motivar e estabelecer estreitamento com a comunidade universitária.

\section{AGRADECIMENTOS}

Agradecimentos especiais a excelentíssima, professora, Doutora, Diretora do Centro Universitário Campos de Andrade - Uniandrade, e coordenadoras do curso de enfermagem há época. A todos os Docentes e acadêmicos participantes do projeto e leitoras da época.

\section{REFERÊNCIA}

ANDRADE, Marceila de; SILVA, Sueli Ruil da. Administração de quimioterápicos: uma proposta de protocolo de enfermagem. Revista Brasileira de enfermagem, v. 60, n. 3, p. 331-335, 2007.

ANDRADE, Yara Nayá Lopes de et al. Conhecimento de acadêmicos de enfermagem sobre o ensino-aprendizagem da Sistematização da Assistência de Enfermagem. Rev Rene, v. 17, n. 5, p. 602-609, 2016.

BRÁS, Cláudia; FERREIRA, Manuela. A comunicação e qualidade de cuidados em enfermagem: revisão de literatura. CIAIQ2016, v. 2, 2016. 
BRÊTAS, José Roberto da Silva; PEREIRA, Sônia Regina. Projeto de extensão universitária: um espaço para formação profissional e promoção da saúde. Trabalho, educação e saúde, v. 5, n. 2 , p. 367-380, 2007.

BUENO, Wilson Costa. Comunicação cientifica e divulgação científica: aproximações e rupturas conceituaiss. Informação \& Informação, v. 15, n. 1esp, p. 1-12, 2010.

ERDMANN, Alacoque Lorenzinni; FERNANDES, Josicelia Dumêt; TEIXEIRA, Giselle Alves. Panorama da educação em enfermagem no Brasil: graduação e pós-graduação. Enfermagem em Foco, v. 2, n. SUP, p. 89-93, 2011.

FERREIRA, Wellington Fernando da Silva et al. A judicialização da saúde e suas dimensões na gerontologia: uma contribuição da enfermagem. Revista Saúde e Desenvolvimento, v. 11, n. 9, p. 249-266, 2017.

FONTENELE, Rafael Mondego et al. Comunicação ineficaz e suas consequências para o paciente grave. Revista Científica de Enfermagem-RECIEN, v. 9, n. 27, 2019.

GANTOS, Marcelo Carlos; ZAGANELL, Bárbara Martins. Extensão universitária, comunicação e divulgação científica: A experiência do Jornal Universitário UENF ONLINE (2002-2012). Revista ELO-Diálogos em Extensão, v. 2, n. 1, 2013.

GARCIA, Ana Paula Rigon Francischetti et al. Processo de enfermagem na saúde mental: revisão integrativa da literatura. Revista Brasileira de Enfermagem, v. 70, n. 1, p. 220-230, 2017.

GIL, Antonio Carlos. Como elaborar projeto de pesquisa. 4.ed. São Paulo: Atlas, 2002.

GIL, Antonio Carlos; YAMAUCHI, Nancy Itomi. Elaboração do projeto na pesquisa fenomenológica em enfermagem. Revista Baiana de Enfermagem!, v. 26, n. 3, 2012.

GOMES, Maria Paula Cerqueira et al. O uso de metodologias ativas no ensino de graduação nas ciências sociais e da saúde: avaliação dos estudantes. Ciência \& Educação (Bauru), v. 16, n. 1, p. 181-198, 2010. 
HONÓRIO, Rita Paiva Pereira; CAETANO, Joselany Afio. Elaboração de um protocolo de assistência de enfermagem ao paciente hematológico: relato de experiência. Revista Eletrônica de Enfermagem, v. 11, n. 1, 2009.

HUNGER, Dagmar et al. O dilema extensão universitária. Educação em revista, v. 30, n. 3, p. 335-354, 2014

LEITE, Alice Iana Tavares et al. A importância de ser ético: da teoria à prática na enfermagem. Cogitare Enfermagem, v. 14, n. 1, 2009.

LESSA, Andréa Broch Siqueira Lusquinhos; ARAÚJO, Cristina Nunes Vitor de. A enfermagem brasileira: reflexão sobre sua atuação política. Revista Mineira de Enfermagem, v. 17, n. 2, p. 474-481, 2013.

MARANHÃO, Joyce Hilario; MOURA, Francisca Jéssika Nunes; PINHEIRO, Eliziê Pereira. O Papel das extensões na educação e no cotidiano dos estudantes da área de saúde: construção de novas práticas. In: $\mathbf{1 1}^{\mathbf{0}}$ Congresso Internacional da Rede Unida. 2014.

MENDES, Aida Cruz et al. Educação em enfermagem de saúde mental e psiquiatria no curso de licenciatura em enfermagem. SMAD Revista Eletrônica Saúde Mental Álcool e Drogas (Edição em Português), v. 14, n. 2, p. 73-83, 2018.

MOTA, Marina Soares et al. Reações e sentimentos de profissionais da enfermagem frente à morte dos pacientes sob seus cuidados. Revista Gaúcha de Enfermagem, v. 32, n. 1, p. 129-135, 2011.

OLIVEIRA, Maria Luiza Carvalho de; SILVA, Nair Chase da. Estágio de docência na formação do mestre em enfermagem: relato de experiência. Enfermagem em Foco, v. 3, n. 3, p. 131-134, 2012.

OLIVEIRA, Stefanie Griebeler; QUINTANA, Alberto Manuel; BERTOLINO, Karla Cristiane Oliveira. Reflexões acerca da morte: um desafio para a enfermagem. Revista Brasileira de Enfermagem, v. 63, n. 6, p. 1077-1080, 2010.

PECHULA, Marcia Reami et al. Divulgação científica em extensão: experiências do jornal Biosferas na relação entre comunicação, educação e sociedade. Revista Brasileira de Extensão Universitária, v. 7, n. 2, p. 91-98, 2016. 
PEREIRA, Bianca Damas; MARTINS, Rafael Barbosa Fialho; LANNES, Joaquim Sucena. Dez anos do jornal-laboratório OutrOlhar: a história de um projeto de extensão que dá certo. Revista ELO-Diálogos em Extensão, v. 2, n. 1, 2013.

PERSEGONA, Karin Rosa et al. O conhecimento político na atuação do enfermeiro. Escola Anna Nery, v. 13, n. 3, p. 645-650, 2009.

PIMENTEL, Vera; MOTA, Dálete Delalibera Corrêa de Faria; KIMURA, Miako. Reflexões sobre o preparo para a docência na pós-graduação em enfermagem. Revista da Escola de Enfermagem da USP, v. 41, n. 1, p. 161-164, 2007.

QUEMEL, Glenda Keyla China et al. Metodologias Ativas de Aprendizagem: construção de diagnósticos de enfermagem sobre um estudo de caso. Revista Eletrônica Acervo Saúde, n. 25, p. e826-e826, 2019.

ROSENSTOCK, Karelline Izaltemberg Vasconcelos et al. Aspectos éticos no exercício da enfermagem: revisão integrativa da literatura. Cogitare Enfermagem, v. 16, n. 4, p. 727-733, 2011.

RUÃO, Teresa; LOPES, Felisbela; MARINHO, Sandra. Comunicação e saúde, dois campos em intersecção. Comunicação e sociedade, p. 5-7, 2012.

RUIZ-MORENO, Lídia et al. Jornal Vivo: relato de uma experiência de ensino-aprendizagem na área da saúde. Interface-Comunicação, Saúde, Educação, v. 9, n. 16, p. 195-204, 2005.

SANCHES, Rafaely de Cassia Nogueira et al. Percepções de profissionais de saúde sobre a humanização em unidade de terapia intensiva adulto. Escola Anna Nery Revista de Enfermagem, v. 20, n. 1, p. 48-54, 2016.

SANTANA, Júlio César Batista et al. Ética e humanização da assistência em um serviço de atendimento pré-hospitalar: o que pensam os profissionais de saúde. Revista de Pesquisa Cuidado é Fundamental Online, v. 4, n. 4, p. 2744-2754, 2012.

SANTANA, Júlio César Batista. Avanços tecnológicos e os limites dentro de uma Unidade de Terapia Intensiva no processo ético do cuidar: significado para os acadêmicos de enfermagem. Rev Bioethikos, v. 2, n. 1, p. 73-80, 2008. 
SANTOS, Alex Mota et al. "Aprender fazendo" cartografias: Relatos de experiência através da extensão universitária. Revista Conexão UEPG, v. 16, p. 1-13, 2020.

SANTOS, Margarida Custódio dos et al. Comunicação em saúde e a segurança do doente: problemas e desafios. Revista portuguesa de saúde pública, p. 47-57, 2010.

SILVA, Mayara Santos et al. A enfermagem no campo da saúde mental: uma breve discussão teórica. Revista Amazônia Science \& Health, v. 5, n. 2, p. 40-46, 2017.

SIMÕES, Ana Lúcia Assis. Enfermagem: uma profissão de múltiplas dimensões. Revista de Enfermagem e Atenção à Saúde, v. 5, n. 1, 2016.

SOUZA, Juliana de oliveira; DE OLIVEIRA, Bruno Castro. A influência do PET-Saúde na formação do estudante de Fisioterapia: relato de experiência. Ciência \& Saúde, v. 8, n. 2, p. 94-97, 2015.

TESTI, Carolina Valeriano et al. Formação acadêmica e a prática profissional de enfermagem: interfaces para reflexão. Revista Baiana de Saúde Pública, v. 38, n. 1, p. 155, 2014.

VOGEL, Karolyne Pricyla et al. Comunicação de más notícias: ferramenta essencial na graduação médica. Revista Brasileira de Educação Médica, v. 43, n. 1, p. 314-321, 2019.

YUZAWA, Lucineia Satiko; FERREIRA, Wellington Fernando da Silva; OLIVEIRA, Elia Machado de. Políticas públicas brasileira de imunização e educação permanente: um recorte temporal bioético/ Brazilian Public Policies on Immunization and Permanent Education: A Temporary Bioethic Cutting. ID ON LINE REVISTA DE PSICOLOGIA, v. 13, n. 45, p. 95-110, 2019.

ZANOTTI, Susane Vasconcelos et al. Jornal do CAPS: Construção de histórias em Oficinas Terapêuticas. Psico, v. 41, n. 2, 2010. 